Byrne, R.M.J. (1989). Suppressing valid inferences with conditionals. Cognition, 31, 61-83

\title{
Suppressing valid inferences with conditionals
}

RUTH M.J. BYRNE

MRC Applied Psychology Unit,

Cambridge

Abstract

Three experiments are reported which show that in certain contexts subjects reject instances of the valid modus ponens and modus tollens inference form in conditional arguments. For example, when a conditional premise, such as: If she meets her friend then she will go to a play, is accompanied by a conditional containing an additional requirement: If she has enough money then she will go to a play, subjects reject the inference from the categorical premise: She meets her friend, to the conclusion: She will go to a play. Other contexts suppress the conditional fallacies. The first experiment demonstrates the effect of context on conditional reasoning. The second experiment shows that the inference suppression disappears when the categorical premise refers to both of the antecedents, such as: She meets her friend and she had enough money. In this case, subjects make both the valid inferences and the fallacies, regardless of the contextual information. The third experiment establishes that when subjects are given general information about the duration of a situation in which a conditional inducement was uttered, such as: If you shout then I will shoot you, they reject both the valid inferences and the fallacies. The results suggest that the interpretation of premises plays an even more central role in reasoning than has previously been admitted.

I am grateful to Mark Keane and Phil Johnson-Laird for their discussions, criticisms and developments of this work and for their improvements to many drafts. I am indebted to Alan Garnham, Angus Gellatly, Ken Gilhooly, Nick McDonald, David Shanks, Patrizia Tabossi, and the referees for their comments on previous versions, and to Ian Nimmo-Smith for statistical advice. My thanks are also due to Paul and Mary Byrne, Lisa Fitzgerald, Paul Deighan, and Steven and Jenny Fitzgerald. This research was conducted in partial fulfillments of the requirements for a $\mathrm{PhD}$ while I was in receipt of a postgraduate award from the University of Dublin, Trinity College, Republic of Ireland. 


\section{Introduction}

Some inferences are so easy to make that their validity is indisputable. Consider a conditional sentence of the form:

If she has an essay to write then she will study late in the library, and a categorical sentence of the form:

She has an essay to write.

It is clear that one can reach a conclusion of the form:

She will study late in the library.

This inference, which logicians call modus ponens, is so self-evident that it has been made a central principle not only in propositional logic (e.g., Copi, 1982) but also in many modern logics (Haack, 1978). Modus ponens is a valid form of inference, and in experiments people judge it to be so (for reviews see Evans, 1982; Wason \& JohnsonLaird, 1972). What can be problematic, however, is exactly which inferences expressed in ordinary language, count as instances of modus ponens. One such case is where an inference leads not to a conclusion, but to a question. For example, from the premises:

If Lis a comes to the party, will she bring her husband?

Lis a comes to the party,

it is not clear what one could conclude. There are also difficult cases (cf. JohnsonLaird, 1983) where the conditional appears to have the truth conditions of a simple assertion, such as:

If you need some money, there is $\$ 20$ in your pocket.

This conditional seems to be true or false simply depending on whether or not the consequent is true: There is $\$ 20$ in your pocket. The conditional could be true in the same context as another:

If there is \$20 in your pocket, you don't need any money.

Modus ponens inferences from both conditionals yield the conclusion:

If you need some money, you don't need any money,

which seems wrong. Conversely, there are cases where modus ponens seems to apply even when there is no explicit conditional premise. Consider a parent, observing a child about to take yet another biscuit, who says: I'll be annoyed. This assertion has the force of a conditional: If you take a biscuit then I'll be annoyed. 
Until we have established what counts as an instance of a particular inference, we cannot assess subjects' ability to make that inference. Indeed it is sometimes not at all obvious what should count as an exact instance of any of the inference forms that logicians have identified. Consider a second inference form, which is also sanctioned within propositional logic, and is called modus tollens. From the premises:

If she has an essay to write then she will study late in the library.

She will not study late in the library,

a valid conclusion is:

She does not have an essay to write.

Many people also judge this conclusion to be valid, although they find it is a more difficult inference (e.g., Evans, 1982).

Granted that people are capable, on occasion, of making inferences of these two forms, a crucial question is how they do so, that is, what mental processes underlie their performance. Historically, logicians such as Frege first proposed prooftheoretic methods of assessing inferences. They described formal rules of inference, that is, rules that are independent of the content of variables (cf. Copi, 1982). Subsequently, logicians proposed a semantic, model-theoretic method of assessing inferences. They showed how to construct models which captured the content of premises, and how validity could be tested by a search for counterexamples to a putative conclusion (e.g., Beth, 1971). In the psychology of human reasoning, a similar distinction between formal and semantic theories has arisen.

A major class of theories suggests that reasoning depends on formal rules of inference that operate in a syntactic way on the abstract logical form of the premises (e.g., Braine, 1978; in press; Braine, Reiser \& Rumain, 1984;Osherson, 1975; Rips, 1983a, 1988; Sperber \& Wilson, 1986). Hence, formal theories propose that there is a mental logic comprising inference schemas which specify the form of an inference: An inference rule legislates that a certain proposition can be immediately derived when certain other propositions have been established (Braine, 1978, pp.3-4). The theories are intended to be psychologically plausible adaptations of the "natural deductions" systems of propositional logic. The rules define the elementary deductive steps, and so formal theorists claim that: "the sequence of applied rules forms a mental proof or derivation of the conclusion from the premises, where these implicit proofs are analogous to the explicit proofs of elementary logic" (Rips, 1983b, p.40).

The formal rules are uninterpreted patterns into which the input must be translated, and hence before they can be used in reasoning there must be a 
comprehension step in which the premises are decoded into the representations used by the rules (see Braine et al., 1984, p. 317). Formal theorists have focused almost exclusively on specifying the repertoire of rules and so they have yet to provide a systematic account of this comprehension step, which leads to the recovery of the abstract logical form of premises.

The fact that people make systematic errors in reasoning is worrying for formal theorists; although some theorists have included faulty inference rules corresponding to fallacious inferences (e.g., Von Domarus, 1944), most do not. Yet people do make mistakes and a theory of inference has to explain not only valid reasoning but also erroneous reasoning. Aside from mistakes made through fatigue, boredom, and so on, two errors are particularly common in conditional reasoning. One error is the denial of the antecedent. Consider the premises:

If she has an essay to write then she will study late in the library.

She does not have an essay to write.

The fallacy is to conclude:

She will not study late in the library.

The second error is the affirmation of the consequent. Consider the premises:

If she has an essay to write then she will study late in the library.

She will study late in the library.

The fallacy is to conclude:

She has an essay to write.

These systematic errors do not refute formal theories but they are difficult for them to explain, since they presumably cannot be attributed to the operation of corresponding inference rules. Instead, proponents of formal theories attribute the errors to comprehension processes (e.g., Marcus \& Rips, 1979; Rips \& Marcus, 1977; Staudenmayer, 1975). For example, Rumain, Connell, and Braine (1983, p.481) argue that the fallacies are not sanctioned as rules within the formal schemas; instead "they are conversational implicatures ... that is, due to the 'logic of conversation', not to the logical properties of subjects' representation of if." The fallacies are invited by our understanding of language and by our general knowledge (e.g., Braine \& Rumain, 1983; Fillenbaum, 1978; Geis \& Zwicky, 1971; Grice, 1975; Levinson, 1983; Markovits, 1984, 1985). Comprehension processes which are sensitive to discourse context (Rumain et al., 1983, p.481) ensure that a conditional such as:

If she has an essay to write then she will study late in the library, 
invites its obverse:

If she does not have an essay to write then she will not study late in the library. Hence the formal theorists claim that the fallacy of arguing from the premises:

If she has an essay to write then she will study late in the library.

She does not have an essay to write.

to the conclusion:

She does not study late in the library,

does not come about through the operation of a mental rule corresponding to the denial of the antecedent. Instead it is made through the application of the modus ponens inference rule applied to the obverse of the original sentence.

In conversation, speakers are supposed to give hearers as much information as they need for the current purposes of the exchange (Grice, 1975). In real life, when hearers understand the conditional:

If she has an essay to write then she will study late in the library, they may realize there are alternative possibilities, such as:

If she has some textbooks to read then she will study late in the library. Such a realization would block the acceptance of the obverse of the first conditional and so they would not make the fallacious inferences. In contrast, in an experimental setting, subjects receive no information about possible alternatives and so the fallacies are frequently made. Many theorists, particularly those working in a Piagetian tradition, emphasize that awareness of alternative possibilities is necessary for the operation of the formal inference rules (see Markovits, 1984, p. 368; O’Brien \& Overton, 1989, p.46).

To support their explanation of how people make errors, some formal theorists have considered the conditions under which the fallacies are suppressed. They have demonstrated that when a conditional is accompanied by an alternative antecedent, people reject the fallacies (Markovits, 1984, 1985; Rumain et al., 1983). For example, given the premises:

If she has an essay to write then she will study late in the library.

If she has some textbooks to read then she will study late in the library.

She does not have an essay to write,

people do indeed reject the denial of the antecedent. They do not conclude:

She will not study late in the library. 
Presumably, they know that the alternative:

She has some textbooks to read,

could be the case and so could warrant the opposite conclusion. The same suppression occurs for the affirmation of the consequent. Given the premises:

If she has an essay to write then she will study late in the library.

If she has some textbooks to read then she will study late in the library.

She will study late in the library

people reject the conclusion:

She has an essay to write,

presumably because they know the alternative:

She has some textbooks to read,

could be the case instead. These alternative antecedents may, or may not, be mutually exclusive, but each is sufficient for the consequent.

In short, formal theories are not embarrassed by the fallacies, because they can be suppressed by alternatives, and this suppression supports their claim that there are no formal rules corresponding to the fallacies: they arise as a result of the interpretation of the premises. Thus, for example, Rumain et al. (1983, p. 480) write:

... subjects' lexical entry for if must contain information that marks modus ponens as a necessary inference but that does not mark the fallacies (or the invited inference if not $p$ then not $q$ that leads to the fallacies) as more than invited ... Suppose, however, that the valid inferences could be similarly suppressed. Could we then argue that such a finding shows that there are no formal rules corresponding to modus ponens and modus tollens, and that these inferences also arise from the interpretation of the premises? Perhaps not. Before we can consider this issue, the suppression of the valid inferences needs to be demonstrated, and that is the main goal of this paper.

\section{Experiment 1}

In an experimental setting, all of the relevant information necessary for an inference appears to be provided by the materials. Thus, the premises:

If she has an essay to write then she will study late in the library.

She has an essay to write, 
support the modus ponens conclusion:

She will study late in the library.

In daily life, however, people may consider that certain other conditions are necessary for this conclusion to hold, for example, the library must remain open. Thus, conditionals are frequently elliptical in that information that can be taken for granted is omitted from them. Consider the premises above accompanied by another conditional, such as:

If she has an essay to write then she will study late in the library.

If the library stays open then she will study late in the library.

She has an essay to write.

People may reject the conclusion:

She will study late in the library, since the possibility that the library does not stay open casts doubt on this conclusion. The second conditional refers to some additional requirement that must also hold, and so we will call it an additional antecedent. The aim of the first experiment is to examine whether the valid inferences can be suppressed as well as the fallacies.

\section{Method}

Design and materials

There were three groups of subjects in the experiment: One group received simple conditional arguments; a second group received conditional arguments accompanied by a conditional containing an alternative antecedent, and the third group received arguments accompanied by a conditional containing an additional antecedent. All subjects received four sorts of conditional argument: modus ponens, modus tollens, denial of the antecedent and affirmation of the consequent. Each sort of argument was presented with three different contents, making a total of 12 arguments, which were presented in a different random order to each subject.

The three domains of mundane events were devised to be intuitively plausible scenarios (see the Appendix). Each argument was accompanied by three conclusions, for example:

(a) She will study late in the library.

(b) She will not study late in the library.

(c) She may or may not study late in the library. 


\section{Procedure}

Subjects were tested in groups of between five and ten people. They received the 12 items in a single booklet with specific instructions printed on the front page. For all subjects these instructions explained the task with reference to a simple argument as an example. They were asked to assume that the premises were true and to "choose one of the conclusions - (a), (b) or (c) - whichever you think follows from the sentences." Subjects were asked to read each item carefully and to work from beginning to end at their own pace without changing any responses or skipping any items.

\section{Subjects}

The 24 subjects, from Trinity College, University of Dublin, Republic of Ireland, who participated in this experiment were randomly assigned to the three groups $(n=8)$. None had received tuition in logic. Four subjects were replaced because of their failure to complete more than three-quarters of the arguments. These replacements were made during the course of the experiment, prior to any data analysis.

\section{Results and discussion}

Table 1 presents the percentages of inferences made by subjects from the three kinds of arguments. As it shows, subjects' performance was in accordance with the predictions.

Table 1. The percentages ${ }^{*}$ of inferences made as a function of the type of contextual information given in Experiment 1

\begin{tabular}{lllll} 
Argument type & $\begin{array}{l}\text { Modus } \\
\text { ponens }\end{array}$ & $\begin{array}{l}\text { Mnference type } \\
\text { Modus }\end{array}$ & $\begin{array}{l}\text { Denial of } \\
\text { antecedent }\end{array}$ & $\begin{array}{l}\text { Affirmation of } \\
\text { consequent }\end{array}$ \\
\hline Simple arguments & 96 & 92 & 46 & 71 \\
Alternative arguments & 96 & 96 & 4 & 13 \\
Additional arguments & 38 & 33 & 63 & 54 \\
\hline
\end{tabular}

${ }^{*}$ Each percentage is based on the responses of eight subjects to three items

They refrained from making each of the conditional inferences in the appropriate contexts. The interaction between the argument type and inference type, $F(6,63)=$ $13.5, p<.01$, revealed by an analysis of variance is most informative. It reveals that additional antecedents suppressed modus ponens and modus tollens 
while alternative antecedents suppressed the denial of the antecedent and affirmation of the consequent. Subjects made fewer modus ponens inferences from additional arguments (37.5\%) than from simple arguments, 96\%, $t(84)=4.32, p<.001$ shown by one-tailed planned comparisons, Winer (1971). They made fewer modus tollens inferences from additional arguments (33\%) than from simple arguments, 92\%, $t(84)$ $=4.32, p<.001$. Additional antecedents had no effect on the denial of the antecedent or affirmation of the consequent inferences, of course, $t(84)=1.233, p>.05$ for both comparisons. Instead, alternative antecedents affected the fallacies. Alternative arguments led to fewer denials of the antecedent (4\%) than did simple arguments, $46 \%, t(84)=3.08, p<.001$. Subjects also made fewer affirmation of the consequent inferences from alternative arguments (12.5\%) than from simple arguments, $71 \%, t$ $(84)=4.315, p<.001$. Alternative antecedents had no effect on the modus ponens and modus tollens inferences, of course, $t(84)=0.00$ and $t(84)=.308$ respectively, $p$ $>.05$ for both comparisons.

There was a main effect of argument type, $F(2,21)=7.48, p<.01$, showing that more inferences were made from simple arguments (76\%) than from either alternative arguments (52\%) or from additional arguments (47\%). There was also a main effect of inference type, $F(3,63)=14.6, p<.01$, indicating that overall they made fewer denial of the antecedent (38\%) and affirmation of the consequent (46\%) inferences than modus ponens (77\%) and modus tollens (74\%) inferences.

Might the results be a product of the instructions? They were deliberately open in their requirement to say "what follows" and neither stressed the need for logically necessary conclusions nor explained the notion. Yet this openness does not seem to have affected performance, since the responses to the simple arguments were similar to those in previous studies (see, for example, Evans, 1982).

Evidently, an alternative or additional antecedent in the second conditional must alter the interpretation of the first conditional. An inference might then be suppressed because the relevant formal rule no longer applies to this interpretation of the conditional premises. If so, then suppression should occur whenever people are given these conditionals. A more plausible hypothesis, however, is that suppression depends equally as critically on the categorical information in the premises. Given the premises:

If she meets her friend then she will go to a play.

If she has enough money then she will go to a play, together with the conjunction of both additional antecedents: 
She meets her friend and she has enough money,

even subjects who perceive the need for both conditions to be realized should now be prepared to make the modus ponens inference. An analogous case can be made for the modus tollens inference. Likewise, given the premises:

If she meets her friend then she will go to a play.

If she meets her family then she will go to a play,

and the conjunction of both the negated additional antecedents:

She does not meet her friend and she does not meet her family, subjects should now, once again, draw the fallacious denial of the antecedent conclusion:

She will not go to a play.

An analogous case can be made for the affirmation of the consequent. The next experiment was designed to examine these predictions.

\section{Experiment 2}

\section{Method}

\section{Design and materials}

There were three groups of subjects: One group received simple arguments; a second group received arguments consisting of conditionals with alternative antecedents and a premise that combined both antecedents, and the third group received arguments consisting of conditionals with additional antecedents and a premise that combined both antecedents. The second and third groups were tested in Experiment 1 in the corresponding conditions, and only the subjects in the first group were new to this experiment. Each subject made 12 inferences consisting of three different instances of the four sorts of argument: modus ponens, modus tollens, denial of the antecedent and affirmation of the consequent, which were presented in a different random order. The 12 items were intermingled with 12 filler items.

\section{Procedure}

Immediately after Experiment 1, the subjects in the second group (alternative antecedents and the third group (additional antecedents) carried out the corresponding conditions in the present experiment. The subjects in the first group, who were new to the experiment, were given the same instructions as those given in Experiment 1. 


\section{Subjects}

Eight new subjects from Trinity College, University of Dublin, Republic of Ireland participated in the experiment and were assigned to the first group. None had received tuition in logic.

\section{Results and discussion}

Table 2 presents the percentages of inferences made by the subjects in the three groups. As it shows, the results were in accordance with the predictions. There was no interaction between the argument types and inference types, $F(6,63)=1.36, p>.05$. Consider the fallacies: As Table 2 shows, they were not suppressed by the combined alternatives arguments. It is not the case that subjects made fewer denial of the antecedent inferences from the combined alternatives arguments (79\%) than from simple arguments (46\%). Indeed they made significantly more, $t(84)=2.95, p<.01$ on planned comparisons tests. Similarly, it is not the case that subjects made fewer affirmation of the consequent inferences from combined alternatives arguments (75\%) than from simple arguments (58\%). Instead it appears that the difference is in the opposite direction - although it is not statistically significant: $t(84)=1.48, p>.05$. Now consider the valid inferences: They were not suppressed by the combined additional antecedents. It is not the case that subjects made fewer modus ponens inferences from the combined additional arguments (100\%) than from simple arguments (100\%). Similarly, it is not the case that they made reliably fewer modus tollens inferences from combined additional arguments (67\%) than from simple arguments, $75 \%, t(84)=0.74, p>.05$.

Table 2. The percentages ${ }^{*}$ of inferences made as a function of the type of information given in the conditions of Experiment 2

\begin{tabular}{|c|c|c|c|c|}
\hline \multirow[b]{2}{*}{ Argument type } & \multicolumn{3}{|c|}{ Inference type } & \multirow[b]{2}{*}{$\begin{array}{l}\text { Affirmation of } \\
\text { consequent }\end{array}$} \\
\hline & $\begin{array}{l}\text { Modus } \\
\text { ponens }\end{array}$ & $\begin{array}{l}\text { Modus } \\
\text { tollens }\end{array}$ & $\begin{array}{l}\text { Denial of } \\
\text { antecedent }\end{array}$ & \\
\hline Simple arguments & 100 & 75 & 46 & 58 \\
\hline $\begin{array}{l}\text { Categorical information } \\
\text { about both alternatives }\end{array}$ & 100 & 88 & 79 & 75 \\
\hline $\begin{array}{l}\text { Categorical information } \\
\text { about both additionals }\end{array}$ & 100 & 67 & 83 & 71 \\
\hline
\end{tabular}

\footnotetext{
*Each percentage is based on the responses of eight subjects to three items
} 
72 R.M.J. Byrne

There was no effect of argument type, $F(2,21)=1.05, p>.05$, indicating that there is no reliable difference between the frequency of inferences made from simple arguments (70\%), combined alternatives (86\%), and combined additionals (80\%). There was a main effect of inference type, $F(3,63)=7.97, p<.01$, showing that subjects made more modus ponens inferences overall (100\%) than modus tollens, $77 \%, q(2,63), p<.01$ on a two-tailed Newman-Keuls multiple comparisons test, denial of the antecedent, $69 \%, q(3,63), p<.01$, or affirmation of the consequent, $68 \%, q(4,63), p<.01$.

In this experiment, subjects were given conditionals that contained an alternative or an additional antecedent, and so they presumably interpreted the conditionals accordingly. They nonetheless made the fallacies and the valid inferences from these conditionals when they received categorical information about both antecedents. But in real life situations people are unlikely to be told all of the relevant conditions, and so they would not know whether all of the alternative or additional antecedents are satisfied. Hence, the suppression of conditional inferences demonstrated in Experiment 1 may be faithful to everyday reasoning. People may be genuinely less inclined to make conditional inferences - valid or invalid - than they are in experimental settings.

\section{Experiment 3}

There may be cases where certain specific alternatives or additionals are simply suggested by general knowledge. If so, the inferences would once again be suppressed. In the case of everyday inducements, such as promises, threats or bribes, people normally make both the valid and the invalid inferences (Fillenbaum, 1978). Hence, they should make the modus ponens inference even from the following premises:

During the student protest the policeman said to the student:

If you enter the building I will arrest you.

The student entered the building.

They should infer that it is highly likely that the policeman arrested the student. (The inference is not strictly valid because it has been embedded into a description of an inducement in order to produce more naturalistic materials.) They are presupposing that some additional antecedents have also been satisfied, such as that the protest is still in progress at the time when the student enters the building, and that the policeman is still present and alert. General information about the situation, however, can cast doubt on whether these additional presuppositions are satisfied. One way to ensure that people consider whether or not the additional antecedents are satisfied 
is to indicate that the situation in which the utterance was made was of a very short duration. Thus, the modified description:

During the 15-minute student protest the policeman said to the student:

If you enter this building I will arrest you.

The student entered the building,

suggests that the additional antecedents may be false, for example, the protest may no longer be in progress when the student entered the building. If so, the inference will be suppressed. In general, information that a duration was short should make people think about the additional antecedents that are necessary for an inference to be valid. Consequently, they should tend to suppress both the modus ponens and modus tollens inferences.

An analogous effect should occur with the fallacies. Their suppression depends on reasoners' realization that alternative antecedents may bring about the same consequent. Hence, if an event is known to have lasted for a long time, then reasoners are more likely to think of such alternative antecedents. For example, the premises:

During the 2-week student protest the policeman said to the student:

If you enter this building I will arrest you, suggest that other options on the part of the student may result in an arrest. When these alternatives are considered they should suppress the fallacies. Hence, given the categorical premise:

The student did not enter the building, people should be less likely to make the fallacious inference that the policeman did not arrest the student. In general, information that a duration is long should tend to suppress the denial of the antecedent and the affirmation of the consequent. The aim of the third experiment is to test these predictions.

\section{Method}

\section{Materials and design}

There were three groups of subjects: One group received inducements without any information about the duration of the situation; the second received inducements prefaced by information about the long duration of the situation; and the third group received inducements prefaced by information about the shortness of the duration of the situation. Subjects received conditional arguments corresponding to the two valid inferences and to the two fallacies, within each of four contents, concerning promises, 
threats and bribes made by one actor to another (see the Appendix). They were given 16 arguments altogether.

\section{Procedure}

The instructions were identical to those of Experiments 1 and 2, except that the example used was an inducement:

The teacher said to the pupil:

If you misbehave then I will give you extra homework.

The pupil misbehaved.

Did the teacher give the pupil extra homework.

(a) yes

(b) no

(c) maybe

(d) can't say

Subjects were instructed to choose one of the four response choices.

\section{Subjects}

The 24 undergraduates, of Trinity College, University of Dublin, Republic of Ireland, who participated in this experiment were randomly assigned to one of three groups $(n=8)$. Two subjects were replaced because they had studied logic. These replacements were made during the course of the experiment, prior to any data analysis.

\section{Results and discussion}

Table 3 presents the percentages of inferences that subjects made for the three types of arguments. As it illustrates, their performance was as predicted. Most importantly, there was a significant interaction of the argument type and the inference type, $F(6$, $63)=2.2, p<.05$, found by an analysis of variance. One-tailed planned comparisons indicated that the inferences were affected by the types of arguments in accordance with the predictions. The valid inferences were suppressed when they were prefaced by short durational information. Subjects made fewer modus ponens inferences from short duration arguments (41\%) than from no duration arguments, $72 \%, t(84)=2.16$, $p<.05$. They made fewer modus tollens inferences from short duration arguments $(25 \%)$ than from no duration arguments, $66 \%, t(84)=2.8, p<.01$. There were no significant effects of short duration information on the denial of the antecedent or affirmation of the consequent fallacies, as expected, $t(84)=1.29$ and $t(84)=.043$ respectively, $p>.05$ for both comparisons. 
Table 3. The percentages ${ }^{*}$ of inferences made as a function of the kind of durational information prefacing the inducements in Experiment 3

\begin{tabular}{lllll} 
Argument type & $\begin{array}{l}\text { Modus } \\
\text { ponens }\end{array}$ & $\begin{array}{l}\text { Inference type } \\
\text { Modus } \\
\text { tollens }\end{array}$ & $\begin{array}{l}\text { Denial of } \\
\text { antecedent }\end{array}$ & $\begin{array}{l}\text { Affirmation of } \\
\text { consequent }\end{array}$ \\
\hline $\begin{array}{c}\text { Simple arguments } \\
\text { (i.e., no duration) }\end{array}$ & 72 & 66 & 44 & 28 \\
$\begin{array}{c}\text { Alternative arguments } \\
\text { (i.e., long duration) }\end{array}$ & 56 & 59 & 19 & 31 \\
$\begin{array}{c}\text { Additional arguments } \\
\text { (i.e., short duration) }\end{array}$ & 41 & 25 & 25 & 34 \\
\hline
\end{tabular}

*Each percentage is based on the responses of eight subjects to three items

Few fallacies were made in arguments with long duration information.

Subjects made fewer denial of the antecedent inferences from long duration arguments (19\%) than from no duration arguments, $44 \%, t(84)=1.72, p<.05$. They made few affirmation of the consequent fallacies from long duration arguments (31\%). However, few were made even when no duration information was given, $28 \%$, $t(84)=0.2, p>.05$. It is possible that this infrequency may be because of the considerable amount of contextual information already given in the descriptions, by the references to situations and to the actors' roles. Long durations had no significant effect on the valid modus ponens and modus tollens inferences, as expected, $t(84)=$ 1.1 and $t(84)=.043$ respectively, $p>.05$ for both comparisons.

There was no overall reliable difference in the frequency of inferences made in the long duration arguments (41\%), short duration arguments (31\%) and no duration arguments (52\%), as indicated by the non-significant main effect of argument type, $F(2,21)=2.1, p>.05$. There was a main effect of inference type, $F$ $(3,63)=7.8, p<.01$, indicating that, overall, subjects made fewer denial of the antecedent (29\%) and affirmation of the consequent (31\%) inferences than modus ponens $(56 \%)$ and modus tollens (50\%) inferences.

This experiment has demonstrated that both the valid inferences and the fallacies can be suppressed by extra information about the duration of a situation. Even though the inferences in the experiment were embedded in descriptions of discourse, and hence were never truly valid, the subjects drew conclusions based on modus ponens and modus tollens, in the case of simple arguments. Hence the suppression of the inferences is over and above any suppression attributable to the departure from strict validity. Since these arguments are typical 
of the way in which conditionals are used in daily life, it is time to consider exactly what inference suppression can tell us about everyday reasoning.

\section{General discussion}

The experiments have shown that context can suppress both valid and invalid inferences. This finding is in apparent contrast to the view expressed by certain proponents of formal theories: "necessary inferences cannot be countermanded without contradiction whereas invited inferences can be" (Braine \& Rumain, 1983, p. 283), and so it stands in need of explanation.

Most theorists advocating formal rules argue that there are no rules in the mind for fallacious inferences (see Braine, 1978; Osherson, 1975; Rips, 1983a, 1983b). The fallacies arise, they say, from the way in which the premises are understood (see also Clement \& Falmagne, 1986; Henle, 1978). This conjecture appeared to be confirmed by the suppression of the fallacies: "The fact that the invited inferences can be countermanded indicates that the lexical entry for if... cannot be identified with the biconditional" (Rumain et al., 1983, p.475). However, if the suppression of a fallacy implies that there is no corresponding rule in the mind, then, by parity of argument, the suppression of a valid inference implies that there is no formal rule in the mind for it either. Of course, there is no need to accept this view, but, if nothing else, the present results have shown that suppression by itself tells us nothing about the existence or non-existence of rules of inference in the mind.

What processes then are responsible for the suppression of the valid inferences? From the perspective of formal rules, perhaps the most plausible view is that valid inferences are suppressed in the same way as fallacious inferences: The premises are represented so that the usual inference rule cannot be applied to them. Thus, arguments containing alternative antecedents are represented in a disjunctive way, and so premises of the form:

If $\mathrm{p}$ then $\mathrm{q}$.

$$
\text { If } \mathrm{r} \text { then } \mathrm{q} \text {, }
$$

are represented as:

$$
\text { If } \mathrm{p} \text { or } \mathrm{r} \text { then } \mathrm{q} \text {. }
$$

This representation blocks the fallacies. Similarly, arguments containing additional antecedents are represented in a conjunctive way, and so premises of the form: 
If $\mathrm{p}$ then $\mathrm{q}$.

If $\mathrm{r}$ then $\mathrm{q}$,

are represented as:

If $\mathrm{p}$ and $\mathrm{r}$ then $\mathrm{q}$.

And this representation blocks the use of the modus ponens rule, unless both $p$ and $r$ are asserted categorically (see Experiment 2).

This defence of formal rules hinges on the idea that arguments of the same form, such as:

\section{If $\mathrm{p}$ then $\mathrm{q}$.} If $\mathrm{r}$ then $\mathrm{q}$,

are represented in different ways, depending on their semantic content, that is, on whether reasoners construe $p$ and $r$ as alternative or additional antecedents.

Furthermore, the results of Experiment 3 show that conditionals that are understood to have been uttered in the context of an event of a short duration are represented in a different way from the same conditionals uttered during the context of an event of a long duration. Formal theories, therefore, need to be supplemented with a detailed account of the process of interpretation, because premises of the same apparent logical form are represented in different ways depending on their meaning. In short, the burden of explanation shifts from the formal rules to the process of comprehension.

But do people make inferences by relying tacitly on formal rules of inference? The fact that their inferential behavior can be described by a formal rule - making due allowance for the effects of interpretation - does not imply that people must be using a mental equivalent of a formal rule. Instead, as Johnson-Laird $(1983,1986)$ has argued, it seems implausible that people go to considerable lengths to understand premises, and yet are supposed to reason solely on the basis of uninterpreted abstract rules. This peculiarity of formal rules has led some theorists to propose that reasoners rely on content-specific, or at least, domain-dependent rules (see e.g., Anderson, 1983; Cheng \& Holyoak, 1985; Cheng, Holyoak, Nisbett \& Oliver, 1986). The drawback of such schemas for our purposes is that they give no account of how people reason with unfamiliar materials.

Another possibility, entirely compatible with the experimental results, is that reasoners are using a general semantic procedure. Validity is a semantic notion: A valid inference is one in which the conclusion is true (and truth is a semantic notion) in any state of affairs in which the premises are true; an invalid inference is one in which the conclusion could be false in a situation in which the premises are true. Logicians have devised systems in which the validity of an inference 
is established by demonstrating that the conclusion is true in any model of the premises (e.g., Beth, 1971). The same idea underlies the theory of mental models (Johnson-Laird, 1983): People reason by constructing a representation, or model, of a state of affairs, based on the meaning of premises and general knowledge; next, if possible, they formulate a novel conclusion based on the model, and, finally, they search for alternative models of the premises that refute the conclusion. JohnsonLaird and his colleagues have described, and computationally modeled, the sort of lexicon, grammar and procedures that are needed to carry out these three processes. The model-based theory assumes that once one has an adequate explanation of comprehension, there is no need for the mobilization of any elaborate machinery for reasoning, neither of syntactic rules proposed by formal theories, nor of domainspecific rules favored by pragmatic theories. On the contrary, reasoning depends on a search for counterexamples to conclusions, but ordinary individuals do not have a simple deterministic procedure for making such a search (cf. Newell \& Simon, 1972).

Let us consider how this theory explains the suppression of the inferences. A simple indicative conditional of the form:

\section{If $\mathrm{p}$ then $\mathrm{q}$,}

is true if, and only if, $q$ is true in every state of affairs in which $p$ is true (JohnsonLaird, 1986, pp.70-71). Hence it calls for a model in which any instance of $p$ is also an instance of $q$ :

$$
\begin{array}{rr}
p & q \\
p & q \\
& \circ
\end{array}
$$

where each line represents a possible state of affairs. As the model shows, the state of affairs $q$ may occur in the absence of $p$, and since such states may or may not occur, they are tagged with an "o" to indicate that they are optional. The model makes explicit information about $p$ and $q$. Hence, if $p$ is asserted to be the case, it is easy to read off from the model that $q$ must be the case, too: Whichever instance of $p$ is selected, it is always identified with an instance of $q$. In other words, modus ponens can be made directly from the model representing the situations described by the conditional, and without any need for a formal rule. Modus tollens, however, calls for the model to be "fleshed out" with information about the complements of $p$ and $q$ before it can be made.

The integration of a second conditional into a model depends both on the meaning of the conditional and general knowledge. Thus, a conditional of the form: 
If $\mathrm{r}$ then $q$,

has the same consequent as the one in the initial conditional, and so the way in which $r$ will be integrated into the model of the initial conditional depends on general knowledge. Where $r$ is understood as an additional requirement, for example in the premises:

If she meets her friend then she will go to a play.

If she has enough money then she will go to a play,

it will be conjoined with $p$ in the model. Hence, a categorical assertion of $p$ alone will not longer be sufficient for drawing the conclusion $q$. The modus ponens inference will be suppressed. Where $r$ is understood as an alternative antecedent, for example in the premises:

If she meets her friend then she will go to a play.

If she meets her family then she will go to a play, it will be independently identified with instances of $q$. Hence, a categorical assertion or $p$ (or of $r$ ) will suffice for modus ponens, but the fallacies will now be suppressed. Could a single set of experimental findings ever decide between rule-based theories and model-based theories of reasoning? Perhaps not. The moral of these experiments is that in order to explain how people reason, we need to explain how premises of the same apparent logical form can be interpreted in quite different ways. The process of interpretation has been relatively neglected in the inferential machinery proposed by current theories based on formal rules. It plays a more central part, however, in theories based on mental models. 
80 R.M.J. Byrne

\section{Appendix}

Materials used in Experiments 1 and 2

\begin{tabular}{|c|c|}
\hline Antecedent type & Conditional \\
\hline Simple & If she meets her friend then she will go to a play. \\
\hline Alternative & If she meets her family then she will go to a play. \\
\hline Additional & If she has enough money then she will go to a play. \\
\hline Simple & $\begin{array}{l}\text { If she has an essay to finish then she will study late in the } \\
\text { library. }\end{array}$ \\
\hline Alternative & $\begin{array}{l}\text { If she has some textbooks to read then she will study late in the } \\
\text { library }\end{array}$ \\
\hline
\end{tabular}

Additional If the library stays open then she will study late in the library.

Simple If it is raining then she will get wet.

Alternative If it is snowing then she will get wet.

Additional If she goes out for a walk then she will get wet.

Note: Each initial conditional was presented in a simple argument to one group of subjects, accompanied by an alternative to a second group of subjects and by an additional antecedent to a third group.

Materials used in Experiment 3

Information type Inducement

No duration

During the siege, the gunman said to the bank clerk:

If you shout then I will shoot you.

Long During the 2-week siege, the gunman said to the bank clerk:

If you shout then I will shoot you.

Short During the 15-minute siege, the gunman said to the bank clerk:

If you shout then I will shoot you.

No duration

During the seaside trip, the mother said to her son: If you take your sister for a swim then I will buy you an ice cream. 
Long

Short

No duration

Long

Short

No duration

Long

Short
During the 2-week seaside trip, the mother said to her son: If you take your sister for a swim then I will buy you an ice cream.

During the 15-minute seaside trip, the mother said to her son: If you take your sister for a swim then I will buy you an ice cream.

During the student protest, the policeman said to the student: If you enter the building then I will arrest you.

During the two-week student protest, the policeman said to the student: If you enter the building then I will arrest you During the 15-minute student protest, the policeman said to the student: If you enter the building then I will arrest you

During the city-center tour, the tour-guide said to the tourist: If you go shopping then I will lose you.

During the 2 week city-center tour, the tour-guide said to the tourist: If you go shopping then I will lose you.

During the 15-minute city-center tour, the tour-guide said to the tourist: If you go shopping then I will lose you.

Note: One group of subjects received the no-duration description, a second group received the longduration description while a third group received the short-duration description.

\section{References}

Anderson, J. R. (1983). The architecture of cognition. Cambridge, MA: Harvard University Press. Beth, E.W. (1971). Aspects of modern logic. Dordrecht, Hollard: Reidel.

Braine, M. D. (1978). On the relation between the natural logic of reasoning and standard logic. Psychological review, 85(1), 1-21.

Braine, M. D. (in press). The "natural logic" approach to reasoning. In W.F. Overton (Ed.), Reasoning, necessity, and logic: Developmental perspectives.

Braine, M. D., Reiser, B. J., \& Rumain, B. (1984). Some empirical justification for a 
theory of natural propositional logic. In G.H. Bower (Ed.), The psychology of learning and motivation, Volume 18. New York: Academic Press.

Braine, M., \& Rumain, B. (1983). Logical reasoning. In J.H. Flavell and E.M. Markman (Eds.). Handbook of child psychology: Cognitive development. Volume 3, New York, Wiley.

Cheng, P. W., \& Holyoak, K. J. (1985). Pragmatic reasoning schemas. Cognitive psychology, 17(4), 391-416.

Cheng, P. W., Holyoak, K. J., Nisbett, R. E., \& Oliver, L. M. (1986). Pragmatic versus syntactic approaches to training deductive reasoning. Cognitive psychology, 18, 293-328.

Clement, C. A., \& Falmagne, R. J. (1986). Logical reasoning, world knowledge, and mental imagery: Interconnections in cognitive processes. Memory \& Cognition, 14(4), 299-307.

Copi, I.M. (1982). Introduction to logic. (6 ${ }^{\text {th }}$ ed.). London: MacMillan.

Evans, J. (2002). St. BT (1982) The psychology of deductive reasoning. London: Routledge \& Kegan Paul.

Fillenbaum, S. (1978). How to do some things with if. In J.W. Cotton \& R.L. Klatzky (Eds.), Semantic factors in cognition. Hillsdale, NJ: Erlbaum.

Geis, M. L., \& Zwicky, A. M. (1971). On invited inferences. Linguistic inquiry, 11, 561-566.

Grice, H. P. (1975). Logic and conversation. In P. Cole \& J.L. Morgan (Eds.), Syntax and semantics. Volume 3: Speech acts. New York: Academic Press.

Haack, S. (1978). Philosophy of logics. Cambridge: Cambridge University Press.

Henle, M. (1978). Foreword. In R. Revlin and R.E. Mayer (Eds.), Human Reasoning. New York: Wiley.

Johnson-Laird, P. N. (1983). Mental Models. Cambridge: Cambridge University Press.

Johnson-Laird, P. N. (1983). Conditionals and mental models. In C. Ferguson, J.Reilly, A. ter Meulen and E.C. Traugott (Eds.), On Conditionals. Cambridge: Cambridge University Press.

Levinson, S.C. (1983). Pragmatics. Cambridge: Cambridge University Press.

Marcus, S. L., \& Rips, L. J. (1979). Conditional reasoning. Journal of Verbal Learning and Verbal Behaviour, 18, 199-223.

Markovits, H. (1984). Awareness of the 'possible' as a mediator of formal thinking in conditional reasoning problems. British Journal of Psychology, 75(3), 367-376.

Markovits, H. (1985). Incorrect conditional reasoning among adults: Competence or performance? British Journal of Psychology, 76(2), 241-247.

Newell, A., \& Simon, H. A. (1972). Human problem solving. Englewood Cliffs, NJ: Prentice-Hall.

O'Brien, D., \& Overton, W. F. (1980). Conditional reasoning following contradictory evidence: A developmental analysis. Journal of Experimental Child Psychology, 30(1), 44-61.

Osherson, D.N. (1975). Logical abilities in children. Volume 3. Hillsdale. NJ: Elrbaum.

Rips, L. J. (1983a). Reasoning as a central intellective ability. In R.J. Sternberg (Ed.), Advances in the study of human intelligence. Hillsdale: NJ: Erlbaum.

Rips, L. J. (1983b). Cognitive processes in propositional reasoning. Psychological review, 90, 38-71.

Rips, L. J. (1988). Deduction. In R.J. Sternberg and E.E. Smith (Eds.), The psychology of human thought. Cambridge: Cambridge University Press.

Rips, L. J., \& Marcus, S. L. (1977). Suppositions and the analysis of conditional sentences. In M.A. Just and P.A. Carpenter (Eds.), Cognitive processes in comprehension, Hillsdale: NJ: Erlbaum.

Rumain, B., Connell, J., \& Braine, M. D. (1983). Conversational comprehension processes are responsible for reasoning fallacies in children as well as adults: If is not the biconditional. Developmental psychology, 19(4), 471-481.

Sperber, D. \& Wilson, D. (1986). Relevance: Communication and cognition. Cambridge: Cambridge University Press.

Staudenmayer, H. (1975). Understanding conditional reasoning with meaningful propositions. In R.J. Falmagne (Ed.), Reasoning: Representation and process in children and adults. Hillsdale: NJ: Erlbaum

Von Domarus, E. (1944). The specific laws of logic in schizophrenia. In J. S. Kasinin (Ed.), Language and thought in schizophrenia. Berkeley: University of California Press. 
Wason, P. C., \& Johnson-Laird, P. N. (1972). Psychology of reasoning: Structure and content. London: Batsford.

Winer, B.J. (1971). Statistical principles in experimental design ( $3^{\text {rd }}$ ed.) New York: McGraw Hill. 